九州大学学術情報リポジトリ

Kyushu University Institutional Repository

Correlation among Fiber Composition and LDH Isozyme Patterns of the Pectoral Muscles and Flight Habits in Bats

Ohtsu, Ryuichi

Zoological Laboratory, Faculty of Agriculture, Kyushu University

Uchida, Teruaki

Zoological Laboratory, Faculty of Agriculture, Kyushu University

https://doi.org/10.5109/23705

出版情報：九州大学大学院農学研究院紀要. 24 (2/3)，pp. 157-163，1979-11. Kyushu University バージョン：

権利関係 : 
J.Fac. Agr., Kyushu Univ., 24(2•3), 157-163 (1979)

\title{
Correlation among Fiber Composition and LDH Isozyme Patterns of the Pectoral Muscles and Flight Habits in Bats
}

\author{
Ryuichi Ohtsu and Teru Aki Uchida
}

Zoological Laboratory, Faculty of Agriculture,

Kyushu University 46-06, Fukuoka 812

(Received August 8, 1979)

\begin{abstract}
The fiber composition of the pectoral muscles (anterior division) of four bat species with different modes of flight was investigated. The pectoral muscles of Rhinolophus cornutus cornutus which flies slowly and delicately with short-broad wings were composed of three muscle fiber types, while those of Pipistrellus abramus abramus and Myotis macrodactylus that fly at a moderate speed with intermediate wings, and Vespertilio superans superans which flies a long distance with speedy and enduring flights with long-narrow wings were constituted with only one muscle fiber type. Electrophoretic patterns of lactate dehydrogenase (LDH) isozyme were determined in extracts of the pectoral muscles of two species, M. macrodactylus and $V$. s. superans. The pectoral muscles of the former contained LDH-1, LDH-2 and LDH-3, while those of the latter did only LDH-1. It is concluded that there is an apparent relationship among fiber composition and biochemical properties of the pectoral muscles, and flight habits in bats.
\end{abstract}

\section{INTRODUCTION}

Results from a large number of experiments have revealed a close relationship between skeletal muscle function and fiber type composition in terrestrial mammals (reviewed by Close, 1972; Bruke and Edgerton, 1975, etc.), and a number of studies have demonstrated correlations between the biochemical properties of flight muscles and flight behaviour in birds (Wilson et al., 1963 etc.). Bats occupy the unique position of being the only mammals capable of flight. The fliers with different wing-types exhibit different modes of flight. Thus, varied patterns of wing movements and flight abilities should be the manifestations of special adaptations based on certain structural designs in the body as a whole and within the flight muscles themselves.

The most important muscles controlling the downstroke of wings in all bats are the pectoral muscles, which supply suitable materials for the abovementioned inquiries. In our papers (Ohtsu et al., 1978; Ohtsu and Uchida, 1979) we reported the structural and biochemical adaptations for flight in the pectoral muscles of the representative two bat species, Miniopterus schreibersi fuliginosus and Rhinolophus ferrumequinum nippon. The purpose of this study is to determine the fiber composition of the pectoral muscles, to compare the LDH isozyme patterns and further to find a correlation among fiber composition and biochemical properties, and flight habits in bats. 


\section{MATERIALS AND METHODS}

Adults bats of the following species were used : Rhinolophus cornutus cornutus (10 specimens collected at Ibarayama-haikō (an abandoned mine), Fukuoka Prefecture, in May 1977, body weight ca, $7 \mathrm{~g}$ ), which is a slow, highly maneuverable flier having a low wing loading; Pipistrellus abramus abramus (9 specimens collected at Fukuoka City, in June 1978, ca. 7g) and Myotis macrodactylus (9 specimens collected at Ohse-dō Cave, Kumamoto Prefecture, in May 1978, ca. $7 \mathrm{~g}$ ) that are moderate-speed fliers having an intermediate wing loading; and Vespertilio superans superans (10 specimens collected at Ohzukue-jima Islet, Fukuoka Prefecture, in June 1978, ca. $19 \mathrm{~g}$ ), which seems to migrate a long distance and to be a fast flier having a high wing loading. The muscles used here were of the superficial middle portion of the pectoral muscles (anterior division).

Small pieces of muscles were fixed, dehydrated in an alcohol series and embedded in Epon 812 by the same method as described in a previous paper (Ohtsu et al., 1978). Semi-thin sections (1. $5 \mu \mathrm{m}$ ) were made on a Porter-Blume MT-l microtome, and stained with $p$-phenylenediamine according to the
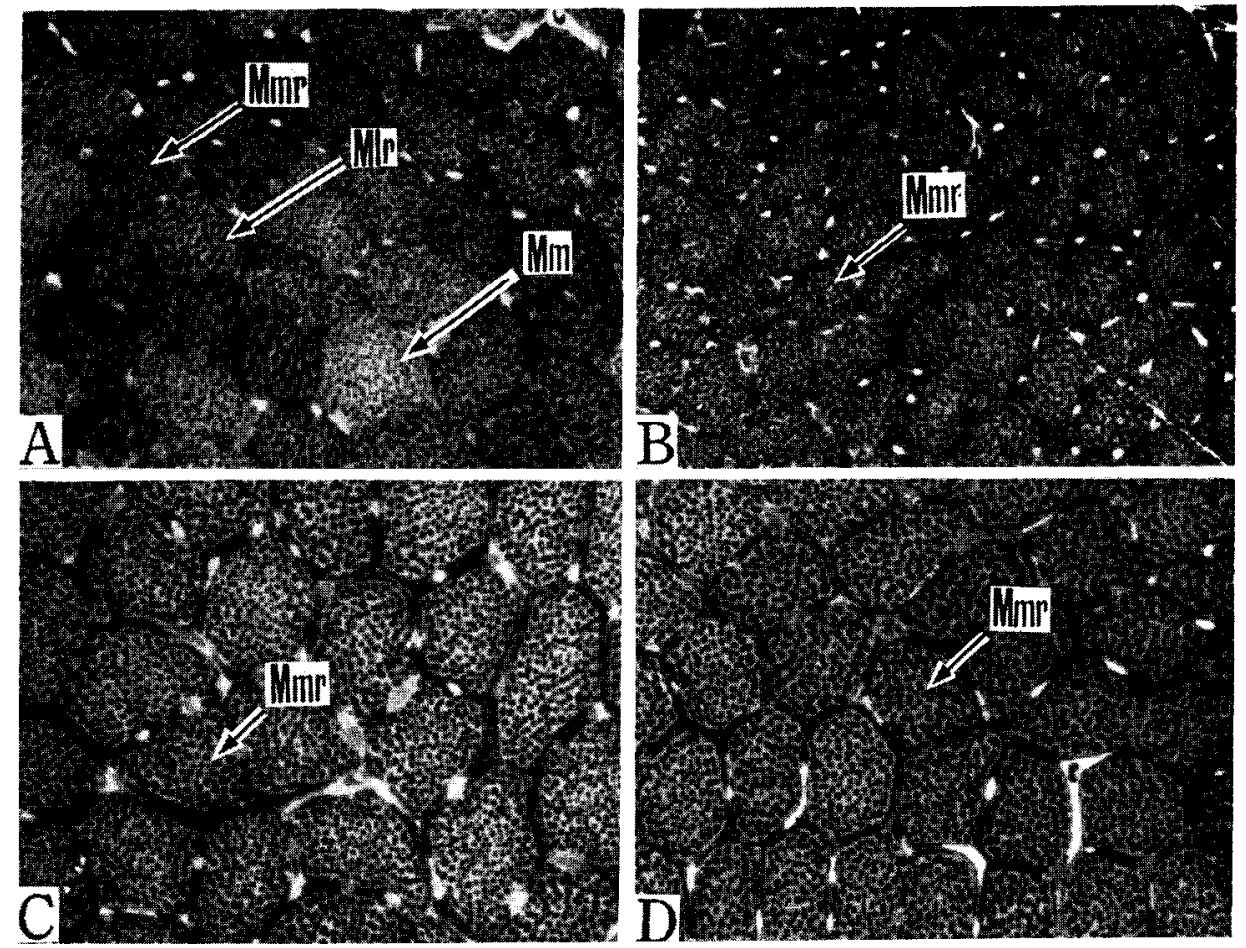

Fig. 1. Cross-sections of the pectoral muscles of bats, stained with pphenylene-diamine. A) R. C. cornutus; B) P. a. abramus; C) M.macrodactylus; D) V. s. superans. Mlr, mitochondria-less rich fiber; Mm. mitochondria-moderate fiber; Mmr, mitochondria-more rich fiber. $\times 700$. 
method of Holländer and Vaaland (1968).

Whole muscles were minced with scissors, suspended in distilled water and homogenized in a Teflon homogenizer. The suspension was centrifuged at $10,000 \times \mathrm{g}$ for $30 \mathrm{~min}$ at $4^{\circ} \mathrm{C}$ and the supernatant was used for electrophoresis. Polyacrylamide disc electrophoresis followed the method of Ornstein (1964) for $1.5 \mathrm{hr}$ at $4^{\circ} \mathrm{C}$. Following electrophoresis, gels were stained for LDH activity by the method of Kitahara et al. (1974).

\section{RESULTS}

\section{Fiber composition of the pectoral muscles}

From the result of $p$-phenylenediamine (PPDA) staining patterns, the pectoral muscles of $\boldsymbol{R}$. $\boldsymbol{c}$. cornutus (Fig. 1A) are composed of three muscle fiber types: i.e., mitochondria-more rich fiber, mitochondria-less rich fiber, and $\mathrm{mi}$ tochondria-moderate fiber, those of $\boldsymbol{P}$. a. abramus (Fig. 1B), M. macrodactylus (Fig. 1C) and V. s. superans (Fig. 1D) are constituted with only mitochondriamore rich fiber.

\section{LDH isozyme patterns of the pectoral muscles}

According to the result of $\mathrm{LDH}$ isozyme patterns, in the pectoral muscles of $\boldsymbol{M}$. macrodactylus (Fig. 2A) three bands (LDH-1, LDH-2 and LDH-3) are present, while in those of $\boldsymbol{V}$. s. superans (Fig. 2B) only one band (LDH-1) is found.



Fig. 2. Electrophoretic patterns of LDH in the pectoral muscles of bats. A) $M$. macrodactylus; B) V. s. superans. An arrow shows the position of the top of small pore gel. The numbers 1,2 and 3 indicate LDH-1,LDH2 and LDH-3 respectively.

\section{DISCUSSION}

George and Naik (1959) attributed a functional significance to a pattern of fiber distribution in the pigeon pectoral muscles, and suggested that white fiber which indulged in fast contraction should be helpful in a quick and sudden action, while the red fiber should be able to contract continuously for a long time as in sustained flight.

Chandra-Bose and George (1965a, b) studied the cellular organization in the pectoral muscles of many birds, and divided the pectoral muscles of birds into six combinations on the basis of the fiber composition and the relative 
distribution of the fiber types. Further, they suggested that the presence of white or intermediate fibers might be regarded as a characteristic of lesser development for sustained flight and that of red fibers of great development. Birds are varied in their flight abilities. The ability suitable for sustained flight is acquired with increase in the number of red fiber. A similar relationship between fiber composition of the pectoral muscles and different flight habits has been reported in several species of bats (George and Naik, 1957; George, 1965; Ohtsu et al., 1978; Ohtsu and Uchida, 1979).

Distinct characteristics in fiber composition of muscles indicate that there must be marked differences in the metabolic requirements of muscles involved in diverse flight types of birds and bats. Muscles with sustained activity must depend on aerobic metabolism, while those contracting during a short period might utilize the energy provided by glycolysis under relative anaerobiosis. It has been revealed that these differences are reflected in the patterns of the LDH isozymes.

In the somatic tissues of mammals, LDH is usually present as up to five electrophoretically distinct isozymes produced from the association of two subunit types ( $M$ and $H$ ) to form the enzymatically active tetramers $M_{4}, M_{3} H$, $\mathrm{M}_{2} \mathrm{H}_{2}, \mathrm{MH}_{3}$ and $\mathrm{H}_{4}$. These isozymes normally differ in catalytic properties, particularly in their sensitivity to substrate inhibition at high pyruvate concentrations. Muscles with a predominantly aerobic metabolism contain isozymes with a high proportion of $\mathrm{H}$ subunits. Isozymes with a high proportion of $\mathrm{M}$ subunits are found in muscles that rely heavily on anaerobic energy production. Wilson et al. (1963) reported that the breast muscle extracts of birds capable of sustained flight presented an isozyme pattern with a predominance of $\mathrm{LDH}-1$, and that other birds of poor fliers exhibited a predominance of LDH-5. Also, a similar correlation between LDH isozyme patterns in pectoral muscles and different flight habits has been reported in several species of bats (Valdivieso et al., 1968; Gutierrez et al., 1974; Kitahara et al., 1974; Muller and Baldwin, 1978; Yokoyama et al., 1979).

Bats that are basically steady-state fliers and seldom display burst activity would have relatively less needs for anaerobic muscle work. This fact has been made clear as follows; in the pectoral muscles of bats, no typical white fiber present commonly in the skeletal muscle of tetradon vertebrates can be found and the concentration of myoglobin was very high (Ohtsu et al., 1978), and LDH-5 was absent (Kitahara et al., 1974).

As to the fiber composition of the pectoral muscles of bats, from the results in this study and the previous papers (Ohtsu et al., 1978; Ohtsu and Uchida, 1979), we classified it into the following three types; a type constituted with mitochondria-more rich, mitochondria-less rich and mitochondria-moderate fibers ( $R$. $f$. nippon and $R$. c. cornutus), a type composed of mitochondriamore rich and mitochondria-moderate fibers ( $M$. s. fuliginosus), and a type consisting of only mitochondria-more rich fiber ( $P$. a. abramus, M. macrodactylus and $V$. s. superans).

The pectoral muscles of $R$. f nippon were in low concentration of myoglobin (Ohtsu et al., 1978) and contained LDH-1, LDH-2, LDH-3, and LDH-4 (Kita- 
hara et al., 1974), and consisted of three fiber types as those of $R$. c. cormutus. But, in the latter the myoglohin concentration is not known. Especially, the presence of the three muscle fiber types in both species is really reasonable from viewpoint of flight habits, which indicates that both species are inferior in the ability of sustained flight but superior in the ability of maneuverability to other bats examined. The fiber diameter of $R$. c. cornutus was smaller than that of $R$. $f$. nippon. In this connection, as described also in many mammalian diaphragms by Gauthier and Padykula (1966), this fact seems to be related to the small body size of the former.

The pectoral muscles of $P$. a. abramus, $M$. macrodactylus, and $V$. s. superans were constituted with only mitochondria-more rich fiber ; nevertheless, according to the result of LDH isozyme analysis, four bands (LDH-1, LDH-2, LDH-3 and LDH-4) were present in P. a. abramus (Kitahara et al., 1974), three bands (LDH-1, LDH-2 and LDH-3) were found in M. macrodactylus, while only LDH-1 was recognized in $V$. s. superans. This indicated that there was a difference in the biochemical properties in spite of the same fiber composition. Consequently, it was revealed that the dependence for aerobic metabolism was highest in $V$. s. superans, lesser in $M$. macrodactylus and least in $P$. a. abramus. As for the fiber diameter, the diameter of mitochondria-more rich fiber in $P$. $a$. abramus was considerably smaller than that in other bats examined. Our attention was paid to this respect. Its small diameter is conductive to efficient oxygen diffusion and fixation, indicating a high metabolic rate in this species.

Although the pectoral muscles of $M$. s. fuliginosus consisted of two muscle fiber types, which had three bands of LDH-1, LDH-2 and LDH-3 (Kitahara et $a l ., 1974)$ and a very high myoglobin concentration $(5.58 \mathrm{mg} / \mathrm{g}$ ) (Ohtsu et al., 1978), this species seemed to be more adapted for sustained flight than $P$. $a$. abramus (myoglobin concentration $3.98 \mathrm{mg} / \mathrm{g}$, unpublished). We did not deal with myoglobin determination in $M$. macrodactylus, and cosequently could not make clear the biochemical difference between $M$. macrodactylus and $M$. $s$. fuliginosus in this respect.

Discussing the flight adaptation of bats, the shape of wings is of importance in determining aerodynamic properties. When speed and endurance are desirable, the wings tend to be long and narrow, wing loading becoming high. When high maneuverability and lift at a low speed are needed, wings are elliptical and relatively broad, wing loading becoming low. Also the presence of bats with intermediate wings has been reported (Vaughan, 1970). $M$. s. fuliginosus with long-narrow wings seemed to be more adapted for fast and sustained flight than $M$. macrodactylus with intermediate wings, taking also into consideration a higher wing loading of the former (0.102) as compared with the latter (0.082) (Kuramoto, 1972).

The pectoral muscles of $V$. s. superans were constituted with only mitochondria-more rich fiber and contained only LDH-1. Further, this species had the highest wing loading (0.132, unpublished) among bats examined. Accordingly, $V$. s. superans seemed to be best adapted for fast and sustained flight, although the determination of myoglobin was not done.

It is concluded that there is an apparent correlation among fiber composi- 
tion and biochemical properties of the pectoral muscles, and flight habits in bats. In other words, this creature offers an example of structural and functional correspondence for the mode of flight in bats.

\section{ACKNOWLEDGMENTS}

We are much indebted to the staff of Zoological Laboratory, Faculty of Agriculture, Kyushu University, for their encouragement and to Professor E. W. Jameson, Jr. of the University of California for comments on the manuscript.

\section{REFERENCES}

Bruke, R. E. and V. R. Edgerton 1975 Motor unit properties and selective involvement in movement. Exercise and Sport Sci. Rev., 3: 31-81

Chandra-Bose, D. A. and J. C. George 1965a Studies on the structure and physiology of the flight muscles of birds. 13. Characterization of the avian supracoracoideus. Pavo, 3: $14-22$

Chandra-Bose, D. A. and J. C. George 1965b Studies on the structure and physiology of the flight muscles of birds. 14. Characterization of the avian supracoracoideus. Pavo, 3: $23-28$

Close, R. 1972 Dynamic properties of mammalian skeletal muscles. Physiol. Rev., 52: 129197

Gauthier, G. F. and H. A. Padykula 1966 Cytological studies of fiber types in skeletal muscle. A comparative study of the mammalian diaphragm. J.Cell Biol., 28: 333-354

George, J. C. 1965 The evolution of the bird and bat pectoral muscles. Pavo, 3: 131-142

George, J. C. and R. M. Naike 1957 Studies on the structure and physiology of the flight muscles of bats. 1. The occurrence of the two types of fibers in the pectoralis major muscle of bat (Hipposideros speoris), their relative distribution, nature of fuel store and mitochondria content. J. Anim. Morphol. Physiol., 4: 96-101

George, J. C. and R. M. Naike 1959 Studies on the structure and physiology of the flight muscles of birds. 5. Observations on the fiber architecture of the pectoralis major muscles of the pigeon. Biol.Bull., 116: 239-247

Gutierrez, M., N. M. G. De Burgos, C. Burgos and A. Blanco 1974 Correlation between muscular lactate dehydrogenase isoenzyme patterns and flight habits of bats. Comp. Biochem. Physiol., 48 : 379-388

Holländer, H. and J. L. Vaaland 1968 A reliable staining method for semi-thin section in experimental neuroanatomy. Brain. Res.,10: 120-126

Kitahara, E., T. A. Uchida and F. Hamajima 1974 LDH isozymes from the standpoint of adaptation for flight in Chiroptera. Zool.Mag., Tokyo, 83: 10-17 (in Japanese with English abstract)

Kuramoto. T. 1972 Studies on bats at the Akiyoshi-dai Plateau. with special reference to the ecological and phylogenic aspects. Bull. Akiyoshi-dui Sci.Mus., (8): 7-119 (in Japanese with English abstract)

Muller, B. D. and J. Baldwin 1978 Biochemical correlates of flying behaviour in bats. Aust. J. Zool., 26: 29-37

Ohtsu, R., T. Möri and T. A. Uchida 1978 Electron microscopical and biochemical studies of the major pectoral muscles of bats. Comp. Biochem. Physiol., 61(A): 101-107

Ohtsu, R. and T. A. Uchida 1979 Further studies on the histochemical and ultrastruc- 
tural properties of the pectoral muscles of bats. J. Fac. Agr., Kyushu Univ., 24: 145-155

Ornstein, L. 1964 Disc electrophoresis-1. Background and theory. Ann. N. Y. Acad.Sci., 121: $321-349$

Valdivieso, D., E. Conde and J. R. Tamssit 1968 Lactate dehydrogenase studies in Puerto Rican bats. Comp. Biochem. Physiol., 27: 133-138

Vaughan, T. A. 1970 The muscular system, flight patterns and aerodynamics. In "Biology of Bats," Vol. I, ed. by W. A. Wimsatt, Academic Press, New York and London, pp. 139-216

Wilson, A. C., R. D. Chan and N. 0. Kaplan 1963 Functions of the two forms of lactic dehydrogenase in the breast muscles of birds. Nature, Lond., 197: 331-334

Yokoyama, K., R. Ohtsu and T. A. Uchida 1979 Growth and LDH isozyme patterns in the pectoral and cardiac muscles of Rhinolophus cornutus cornutus from the standpoint of adaptation for flight. J.Zool., Lond., 187: 85-96 